\title{
Liquid Chromatography/Tandem Mass Spectrometry Method for Quantitation of Cremophor EL and Its Applications
}

\author{
V. Vijaya Bhaskar and Anil Middha \\ Department of Pharmacy, Jagadishprasad Jhabermal Tibrewala University, Vidyanagari, Jhunjhunu, Rajasthan 333001, India \\ Correspondence should be addressed to V. Vijaya Bhaskar; veeravalli.bhaskar@gmail.com
}

Received 25 February 2013; Revised 12 April 2013; Accepted 24 April 2013

Academic Editor: Frantisek Foret

Copyright (c) 2013 V. Vijaya Bhaskar and A. Middha. This is an open access article distributed under the Creative Commons Attribution License, which permits unrestricted use, distribution, and reproduction in any medium, provided the original work is properly cited.

\begin{abstract}
A rapid sensitive and selective MRM based method for the determination of Cremophor EL (CrEL) in rat plasma was developed using liquid chromatography/tandem mass spectrometry (LC-MS/MS). CrEL and polypropylene glycol (internal standard) were extracted from rat plasma with acetonitrile and analysed on C18 column (XBridge, $50 \times 4.6 \mathrm{~mm}, 3.5 \mu \mathrm{m}$ ). The most abundant molecular ions corresponding to PEG oligomers at $\mathrm{m} / \mathrm{z} 828,872,916$ and 960 with daughter ion at $\mathrm{m} / z 89$ were selected for multiple reaction monitoring (MRM) in electrospray mode of ionisation. Plasma concentrations of CrEL were quantified after administration through oral and intravenous routes in male sprague dawley rats at a dose of $0.26 \mathrm{~g} / \mathrm{kg}$. The standard curve was linear (0.9972) over the concentration range of 1.00 to $200 \mu \mathrm{g} / \mathrm{mL}$. The lower limit of quantitation for CrEL was $1.00 \mu \mathrm{g} / \mathrm{mL}$ using $50 \mu \mathrm{L}$ plasma. The coefficient of variation and relative error for inter and intra assay at three QC levels were 0.69 to 9.21 and -7.60 to 4.74 respectively. A novel proposal was conveyed to the scientific community, where formulation excipient can be analysed as qualifier in the analysis of NCEs to address the spiky plasma concentration profiles.
\end{abstract}

\section{Introduction}

In early stages of drug discovery, pharmacokinetic and drug metabolism and disposition studies were conducted in rodents, as they were relatively inexpensive and can be easily acquired and handled [1]. In a typical pharmacokinetic (PK) study, new chemical entities (NCEs) are administered to rats via intravenous and oral routes. Serial blood samples are collected and analysed by liquid chromatography/tandem mass spectrometry (LC-MS/MS). Few NCEs have spiky plasma concentration profiles and various reasons for such profiles could be due to enterohepatic circulation or discrepancies in sample collection/sample processing. Spiky profiles in elimination phase will lead to inaccurate quantification of PK parameters. Extensive studies needed to be carried to characterize enterohepatic circulation behavior of test compounds. Drugs that undergo enterohepatic cycling to a significant extent include colchicine, phenytoin, leflunomide, and tetracycline antibiotics. As formulation excipients have fixed plasma concentration profiles irrespective of NCEs dosed, monitoring the plasma concentration levels of excipient along with NCEs will help to take a decision on the spiky plasma concentration profiles of NCEs. A thoroughly developed and validated bioanalytical method is required to fix the plasma concentration profile and understand the pharmacokinetic disposition of formulation excipient studied. Integrity of results from pharmacokinetic studies can be cross-verified if formulation excipients that had fixed plasma concentration profile/PK parameters are monitored along with the test compound studied. Polyoxyethyleneglycerol triricinoleate (Cremophor EL: CrEL) is a liquid product formed by the reaction of ethylene oxide with castor oil at a molar ratio of $35: 1$ [2]. A major component $(\sim 80 \%)$ of CrEL consists of hydrophobic glycerol polyoxyethylene ricinoleate and polyoxyethylene ricinoleate (Figures $1(\mathrm{a})$ and $1(\mathrm{~b})$ ). The remaining $20 \%$ of CrEL contains $10 \%$ glycerol polyoxyethylene (Figure 1(c)), $7 \%$ free polyethyleneglycol (CrEL-PEG) (Figure $1(\mathrm{~d})$ ), and $3 \%$ nonreacted castor oil [3]. CrEL is used as a excipient in formulations for the solubilization of various hydrophobic drugs including anesthetics [4], antineoplastic agents [4, 5], immunosuppressive agents [6], analgesics [7, 8] vitamins [9], and new synthetic water insoluble compounds. Although 


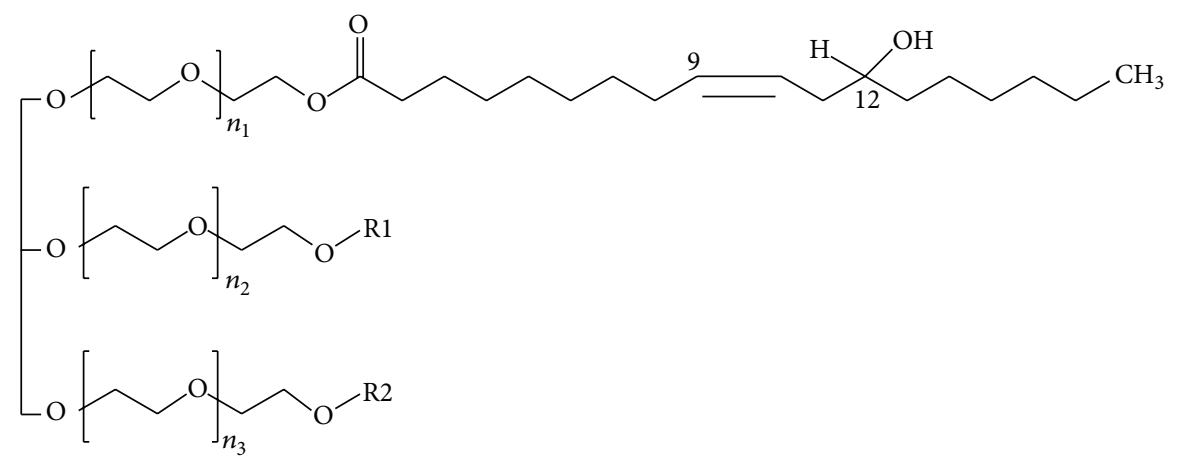

(a)<smiles>[R1]OC(C)(C)COC([Y])(C)COC(=O)CCCCCCCC#CC[C@H]([2H])CCCCCC</smiles>

(b)<smiles>CC(C)OCCOCCOCC(C)(C)CCOCCOCCO</smiles>

(c)<smiles>CC(C)(C)CCO</smiles>

(d)

FIGURE 1: Components of CrEL according to [3]; hydrophobic portion consisting of (a) glycerol polyoxyethylene ricinoleate esters (R1, R2 corresponds to ricinoleic acid). (b) polyoxyethylene ricinoleate esters; hydrophilic portion consisting of (c) glycerol polyoxyethylene ether (d) free polyethyleneglycol.

CrEL is considered relatively nontoxic $[4,10]$, several reports suggest that drugs administered in CrEL induce serious complications like anaphylactoid hypersensitivity [9], axonal swelling, degeneration, and demyelination $[5,6]$. Moreover, it has been proposed that CrEL plays a role in the etiology of peripheral neuropathy observed after intravenous paclitaxel [5] or cyclosporin A treatment and recent evidence supports the notion that CrEL causes nerve conduction $[5,11]$. Pharmacokinetic disposition of drugs depends on CrEL pharmacokinetics [12]. There exists different analytical methods for the quantitative measurement of CrEL such as colorimetric $[4,13]$, chromatographic [14-16], electrophoresis [17], potentiometric [18-21], and pyrolysis mass spectrometry [22]. The colorimetric methods need very tedious preliminary procedures like cleavage and derivatisation of CrEL with an UV absorbing group. The chromatographic and electrophoresis methods need derivatisation and are time consuming. The potentiometric method suffers from limited sensitivity and stability. Pyrolysis mass spectrometry needs different mass spectrometry design, and throughput of analysis was a consideration. In the present work an attempt was made to develop and validate bioanalytical method for the quantitation of CrEL using LC-MS/MS and presented the plasma concentration profiles/PK parameters in male Sprague Dawley rats.

\section{Experimental Section}

2.1. Materials. Cremophor EL, dimethyl sulfoxide (DMSO), and polypropylene glycol (internal standard) were procured from sigma-Aldrich Co. (St. Louis, MO, USA). Acetonitrile, water, and tetrahydrofuran (THF) (HPLC grade) were procured from Merck Specialities Pvt Ltd. (Mumbai, India). Formic acid was procured from Merck specialities pvt ltd (Mumbai, India). Sprague Dawley rats were procured from Bioneeds Ltd. (Bangalore, India). Blood collection vacutainers (Lithium Heparin as anticoagulant) were sourced from BD (Franklin lakes, USA). 
2.2. Preparation of Calibration Standards and Quality Control Samples. Master stock solution of polypropylene glycol (PPG) $(1 \mathrm{mg} / \mathrm{mL})$ (specific gravity: $1.01 \mathrm{~g} / \mathrm{mL}$ ) was prepared in DMSO. Master stock solution of CrEL $(50 \mathrm{mg} / \mathrm{mL})$ (specific gravity: $1.05 \mathrm{~g} / \mathrm{mL}$ ) was prepared in DMSO. Working standard solutions of CrEL-PEG were prepared by serial diluting from master stock with acetonitrile: DMSO : water $(2: 2: 1)$. Working standard solutions were prepared at 25 -fold higher concentration than plasma calibration standards and quality control samples. Plasma calibration standards were prepared at 1.00, 1.50, 5.00, 20.00, 70.00, 120.00, 160.00, 180.00, and $200.00 \mu \mathrm{g} / \mathrm{mL}$, and quality control samples were prepared at three levels, namely, $2.50 \mu \mathrm{g} / \mathrm{mL}$ (LQC, low quality control), 125.00 (MQC, middle quality control) and $162.00 \mu \mathrm{g} / \mathrm{mL}$ (HQC, higher quality control). Calibration standards and quality control samples of CrEL-PEG were prepared by spiking $2 \mu \mathrm{L}$ of the working standard solutions into $48 \mu \mathrm{L}$ of blank rat plasma. Purity details of CrEL were taken into consideration for preparation of calibration standards and quality control samples of CrEL-PEG [3]. The working solution for internal standard $(10 \mu \mathrm{g} / \mathrm{mL})$ was prepared by diluting an aliquot of master stock solution with acetonitrile. Master stock solutions were stored at $4^{\circ} \mathrm{C}$ when not in use.

2.3. Sample Preparation. A $50 \mu \mathrm{L}$ aliquot of plasma (blank control plasma, plasma samples from rats dosed with CrEL, blank plasma spiked with calibration standards, and QC samples) was pipetted into a 96-well polypropylene plate and extracted with $200 \mu \mathrm{L}$ of acetonitrile-containing internal standard. Samples were vortex mixed for $10 \mathrm{~min}$ at $1200 \mathrm{rpm}$ and centrifuged at $3350 \mathrm{~g}$ for $10 \mathrm{~min}$ at $4^{\circ} \mathrm{C}$. $50 \mu \mathrm{L}$ of supernatant was pipette transferred in to a fresh analysis plate and diluted with $450 \mu \mathrm{L}$ of water and $5 \mu \mathrm{L}$ aliquots were injected for LC-MS/MS analysis.

2.4. LC-MS/MS Analysis. All mass spectrometric estimations were performed on a sciex 3200 QTrap triple quadrupole instrument with Turboion Spray (AB Sciex, Toronto, Canada). The HPLC system consisted two of LC20AD UFLC pumps and a SIL HTC autosampler (Shimadzu, Kyoto, Japan). The stationary phase was XBridge C18 with $3.5 \mu \mathrm{m}$ particle diameter (Waters, Ireland). The column dimensions were $50 \times 4.6 \mathrm{~mm}$. The mobile phase flow rate was $1.0 \mathrm{~mL} / \mathrm{min}$. The mobile phase consisted of $0.1 \%$ formic acid in water as aqueous component and acetonitrile with $20 \%$ THF as organic modifier. A generic gradient LC method with a short run time of $3.5 \mathrm{~min}$ was developed for the analysis of CrEL-PEG in plasma samples. The column and autosampler were maintained at $40^{\circ} \mathrm{C}$ and $4^{\circ} \mathrm{C}$, respectively. The Turboion Spray source was operated with typical settings as follows: ionization mode, positive; curtain gas, 20 psi; nebulizer gas (GS1), 50 psi; heater gas (GS2), 50 psi; ionspray voltage, $5500 \mathrm{~V}$; temperature, $550^{\circ} \mathrm{C}$. The molecular ions of CrELPEG and PPG were formed using the declustering potentials of $120 \mathrm{~V}$ and $80 \mathrm{~V}$, respectively. In MRM mode, the most abundant and informative molecular ions corresponding to PEG oligomers (hydrophilic component, CrEL-PEG) were selected at $m / z$ 828, 872, 916 and 960 and fragmented to identical daughter ion at $m / z$ and 89.10 at collision energy of $50 \mathrm{~V}$ with medium CAD gas setting. In MRM mode, the most abundant and informative molecular ions corresponding to glycerol polyoxyethylene ricinoleate (hydrophobic component) were selected at $m / z, 844,888$, 932 , and 976 and fragmented to identical daughter ion at $\mathrm{m} / z$ 307.10. Molecular ion $(m / z$ 906.80) of PPG was fragmented to daughter ion with $\mathrm{m} / z 117.10$ at collision energy of $45 \mathrm{~V}$. Peak areas for all components were automatically integrated using Analyst software version 1.5.

Enhanced scan functions in QTRAP, namely, enhanced MS scan coupled with enhanced product ion (EMS + EPI scan), was used to study the fragmentation pattern of hydrophilic and lipophilic oligomers that were separated in retention on a chromatographic column. A $30 \mathrm{~min}$ LC gradient (time $(\mathrm{min}) / \% \mathrm{~B}=0.01 / 5,2.00 / 5,15.00 / 55,20.00 / 95$, $25.00 / 95,25.01 / 5$, and $30.00 / 5)$ was developed to separate the oligomers on a c18 column $(150 \times 2.0 \mathrm{~mm}, 3.5 \mu \mathrm{m})$ at a flow rate of $0.50 \mathrm{~mL} / \mathrm{min}$. Mobile phase consists of $0.1 \%$ formic acid in water as aqueous component and acetonitrile with $20 \%$ THF as organic component.

2.5. Plasma Stability Determination of CrEL. Master stock solution $(50 \mathrm{mg} / \mathrm{mL})$ of CrEL was prepared in DMSO. $10 \mu \mathrm{L}$ of the master stock was spiked in $490 \mu \mathrm{L}$ of plasma to obtain a final concentration of $1 \mathrm{mg} / \mathrm{mL}$. Samples were incubated for $1 \mathrm{hr}$ at $37^{\circ} \mathrm{C}$ in male sprague dawley rat plasma to determine the plasma stability of the excipient studied. Samples were incubated in Thermomixer (Eppendorf, Germany) at vortex speed of $600 \mathrm{rpm}$. Reaction was terminated at different time points $(5,10,20,40$, and $60 \mathrm{~min})$ by precipitating $50 \mu \mathrm{L}$ of incubation mixture with $200 \mu \mathrm{L}$ of acetonitrilecontaining PPG as internal standard. 0 min control samples were prepared in heat inactivated plasma (heated at $70^{\circ} \mathrm{C}$ for $5 \mathrm{~min}$ ) and $50 \mu \mathrm{L}$ of the sample was precipitated with $200 \mu \mathrm{L}$ of acetonitrile containing PPG as internal standard. Samples were vortex mixed for $10 \mathrm{~min}$ at $1200 \mathrm{rpm}$ and centrifuged at $3350 \mathrm{~g}$ for $10 \mathrm{~min} .50 \mu \mathrm{L}$ of supernatant was transferred into a fresh analysis plate and diluted with $450 \mu \mathrm{L}$ of methanol: water $(1: 1) .5 \mu \mathrm{L}$ aliquots were injected for LCMS/MS analysis.

2.6. Method Validation. Three precision and accuracy batches, consisting of calibration standards (1.00, 1.50, 5.00, $20.00,70.00,120.00,160.00,180.00$, and $200.00 \mu \mathrm{g} / \mathrm{mL}$ ) were analyzed on three different days to complete the method validation. In each batch, QC samples at 2.50, 125.00, and $162.00 \mu \mathrm{g} / \mathrm{mL}$ were assayed in sets of six replicates to evaluate the intra- and interday precision and accuracy. The percentage deviation of the mean from true values, expressed as relative error (RE), and the coefficient of variation (CV) serve as the measure of accuracy and precision, respectively. The selectivity was evaluated by analyzing blank plasma samples obtained from different animals. Extraction efficiency of CrEL-PEG was determined by comparing peak areas of analyte spiked before extraction into the six different lots of plasma with those of the analyte postspiked into plasma extracts. Matrix effect was evaluated from matrix factor 
values. Matrix factor was calculated by dividing mean peak areas of analyte post spiked in to plasma extracts with those of analyte spiked in to neat solutions at three QC levels. To assess post-preparative stability, six replicates of QC samples at each of the low, mid, and high concentrations were processed and stored under autosampler conditions for $24 \mathrm{~h}$ before analysis. To assess bench top stability, six replicates of QC samples at each of the low, mid, and high concentrations were kept at room temperature for $8 \mathrm{~h}$ before analysis. Freeze thaw stability was assessed at three QC levels for three freeze thaw cycles. To assess long-term stability, six replicates of QC samples at each of the low, mid, and high concentrations were kept at $-80^{\circ} \mathrm{C}$ for 90 days before analysis.

2.7. Application. Individual rats (male Sprague Dawley) were dosed at $0.26 \mathrm{~g} / \mathrm{kg}$ intravenously (Bolus) through tail vein and $0.26 \mathrm{~g} / \mathrm{kg}$ orally through oral gavage needle. Dosing volume administered was $5 \mathrm{~mL} / \mathrm{kg}$. The composition of dosing vehicle used for the study was ethanol/CrEL/water $(10: 5: 85, \% \mathrm{v} / \mathrm{v})$ $[23,24]$. Serial blood samples were collected into vacutainers containing lithium heparin (anticoagulant) at 0.08, 0.25, $0.50,1,2,4,8$, and $24 \mathrm{~h}$ postdose [25] after intravenous administration and $0.25,0.50,1,2,4,8$ and $24 \mathrm{~h}$ post dose [25] after oral administration. At each time point $200 \mu \mathrm{L}$ of blood was collected into vacutainers. Blood samples were collected using retro orbital puncture method. Plasma was isolated by centrifugation at $14,850 \mathrm{~g}$ for $10 \mathrm{~min}$ and stored frozen at $-80^{\circ} \mathrm{C}$ until assay. Pharmacokinetic parameters such as elimination rate constant $(\mathrm{Kel})$, half-life $\left(T_{1 / 2}\right)$, extrapolated drug concentration $\left(C_{0}\right), \mathrm{AUC}_{0-\text { last }}, \mathrm{AUC}_{0 \text {-inf }}, \mathrm{AUC}_{\% \text { Extrapolated }}$, volume of distribution $\left(V_{d}\right)$, clearance $(\mathrm{Cl}), T_{\max }, C_{\max }$, and MRT last and absolute bioavailability were calculated using phoenix winnonlin software (v6.3). Absolute bioavailability was calculated using $\mathrm{AUC}_{0-\text { inf }}$ values as $\mathrm{AUC}_{\% \text { Extrapolated }}$ was less than $20 \%$.

\section{Results and Discussion}

3.1. LC-MS/MS Analysis. The electrospray ionization of CrEL produced numerous molecular ions under positive ionization conditions (Figure 2(a)). It was difficult to pick the molecular ion of interest with too many molecular ions showing up in the spectra. Majority of the molecular ions did not produce any distinct fragment ions to analyze in MRM mode of analysis. So, in order to understand the molecular ions that correspond to hydrophilic and hydrophobic portions, tuning solution was injected through LC column in to mass spectrometer. Clear separation was achieved with the developed $30 \mathrm{~min}$ LC gradient (Figure 2(b)). Hydrophilic oligomers corresponding to glycerol polyoxyethylene did not generate any distinct daughter ions, whereas hydrophilic oligomers corresponding to PEG oligomers (Figure 3(a)) generated identical daughter ion with $\mathrm{m} / z 89.10$ (Figure 3(b); fragmentation pattern of one oligomer $\mathrm{m} / \mathrm{z} 960.20$ was represented in the figure, other oligomers also shared similar fragmentation pattern). The molecular ions of PEG oligomers detected were ammonium adducts. For calculating the plasma concentrations of CrEL-PEG as a whole, analyte peak areas of the four oligomers were summed and calibration curve was built. Hydrophobic oligomers corresponding to glycerol polyoxyethylene ricinoleate with molecular ions at $844,888,932$, and 976 (Figure 4(a)) generated distinct daughter ions with $m / z$ 307.10 (Figure 4(b)). Determination of hydrophobic component, although with distinct fragment ions, was not taken up as it was found highly unstable in rat plasma (Figure 4(c)). Glycerol polyoxyethylene component (hydrophilic) was not taken up for analysis as there were no distinct fragment ions produced for any of the oligomers. The electrospray ionization of PPG produced abundant molecular ions at $\mathrm{m} / z 906.70$ (Figure 5(a)) and generated an intense fragment at $117.10 \mathrm{amu}$ (Figure 5(b)). LC-MS/MS method operated with the $\mathrm{C} 18$ column and a 3.5 min generic gradient LC method (Time $(\min ) / \% \mathrm{~B}=0.01 / 5,1.50 / 95,2.50 / 95,2.60 / 5$, and 3.50/5) was developed for the analysis of CrEL-PEG in plasma. Various organic modifiers such as acetonitrile, methanol, and acetone were tested for achieving better peak shape and address the response saturation observed at higher calibration standards for CrEL-PEG. All organic modifiers tested resulted in poor linearity with response saturation at higher calibration standards. However, addition of THF to acetonitrile resulted in better linearity and response saturation was not seen. THF is the solvent of choice for the analysis of many polymers [26,27], but, higher percentages of THF cannot be used practically in LC-MS/MS as it is highly inflammable solvent. So, final mobile phase conditions were optimized to $20 \%$ THF in acetonitrile.

Because of the higher sensitivity of LC-MS/MS method compared to that of HPLC or colorimetric methods, lesser plasma sample volume $(50 \mu \mathrm{L})$ is sufficient to obtain an LLOQ of $1.00 \mu \mathrm{g} / \mathrm{mL}$. Colorimetric methods lacked detection sensitivity with an LLOQ of $500 \mu \mathrm{g} / \mathrm{mL}$. Even though the calibration range of $1 \mu \mathrm{g} / \mathrm{mL}$ to $200 \mu \mathrm{g} / \mathrm{mL}$ was higher for analysis on mass spectrometer, analysis of plasma samples revealed that the plasma concentrations of CrEL was around $1 \mathrm{mg} / \mathrm{mL}$ in the initial sampling points from intravenous route. Therefore, if these study samples have to fit in to the low $\mathrm{ng} / \mathrm{mL}$ standard curve, very high dilution (100-1000-fold) is required, which requires more blank plasma for dilution, which practically is a limitation in drug discovery. So rather than developing a method with high sensitivity, here efforts were put to develop fit for purpose bioanalytical method, by selecting the mass spectrometer (3200 QTRAP) that is not highly sensitive, diluting the precipitated samples 10 -fold after precipitation and injected less volume of sample $(5 \mu \mathrm{L})$. No interference at the retention times of PPG (2.26 min) (Figure 6(a)) and CrEL (1.35 min) (Figure 6(b)) was observed in any of the lots screened as shown in representative chromatogram of the extracted blank plasma sample, confirming the selectivity of the present method. Representative chromatogram of PPG at $10 \mu \mathrm{g} / \mathrm{mL}$ spiked concentration was shown in Figure 6(c). Representative chromatogram of CrEL at LLOQ was shown in Figure 6(d). The LLOQ was set at $1.00 \mu \mathrm{g} / \mathrm{mL}$ for CrELPEG using $50 \mu \mathrm{L}$ of rat plasma. The retention times of CrELPEG and PPG were reproducible throughout the experiment and no column deterioration was observed after analysis of plasma samples. 


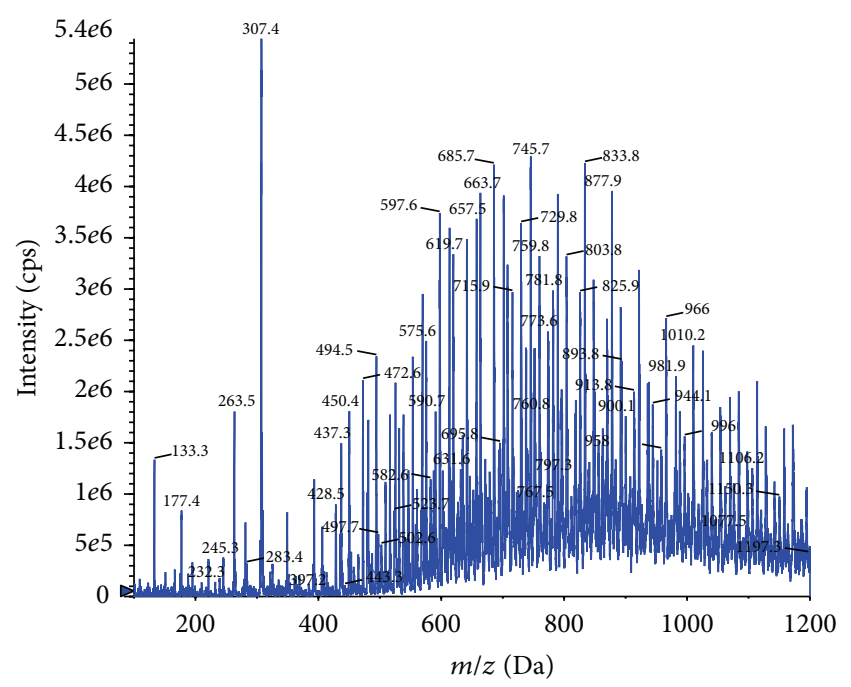

$\square+Q 1: 0.301 \mathrm{~min}$ from Sampl... Max. $5.4 e 6 \mathrm{cps}$.

(a)



(b)

Figure 2: (a) Parent ion (full scan) scan of CrEL. (b) Chromatogram representing the difference in elution pattern of hydrophobic and hydrophilic oligomers of CrEL.



+EMS: $\exp 1,13.37$ to $16 \ldots$ Max. $2.5 e 6 \mathrm{cps}$.

(a)

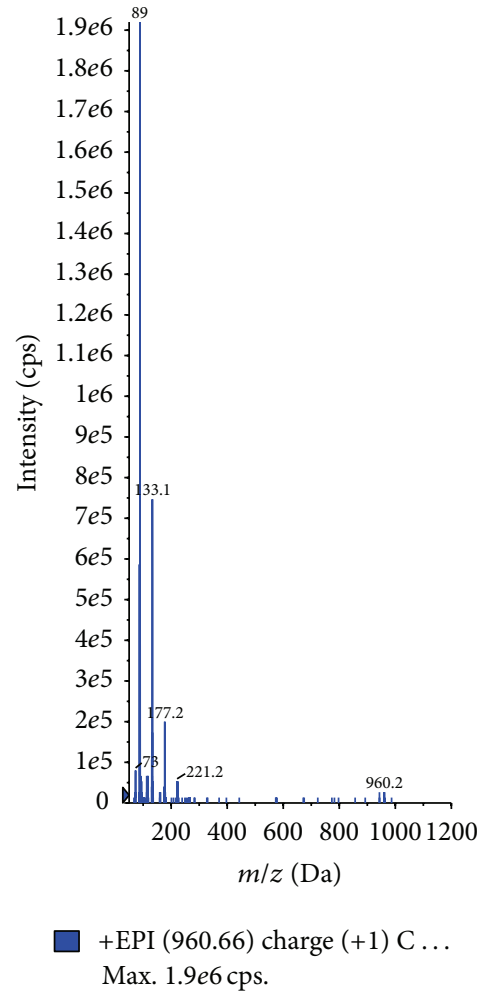

(b)

FIgURE 3: (a) Parent ion scan representing the molecular ions of PEG oligomers of CrEL. (b) Fragmentation pattern of selected oligomer with $\mathrm{m} / z 960.20$. 


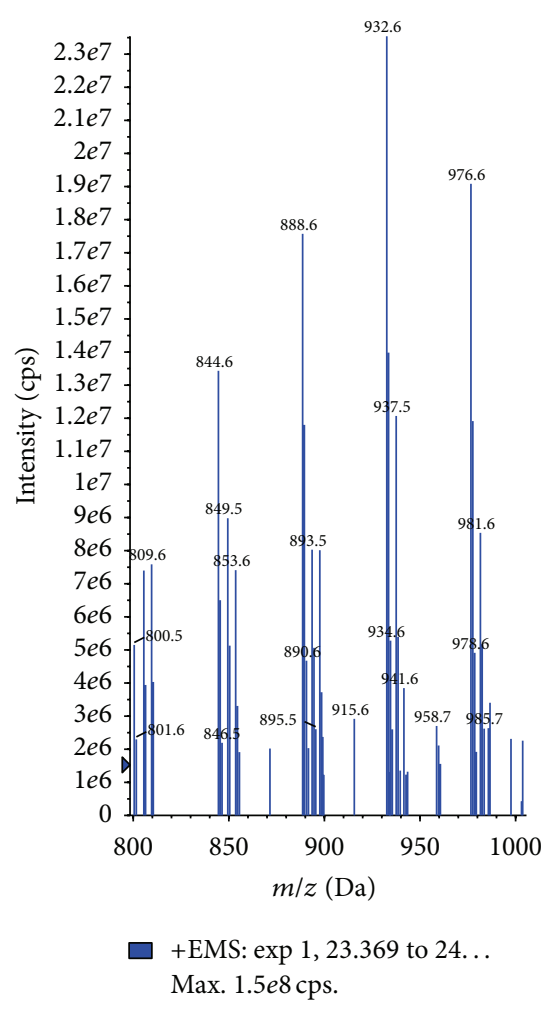

(a)

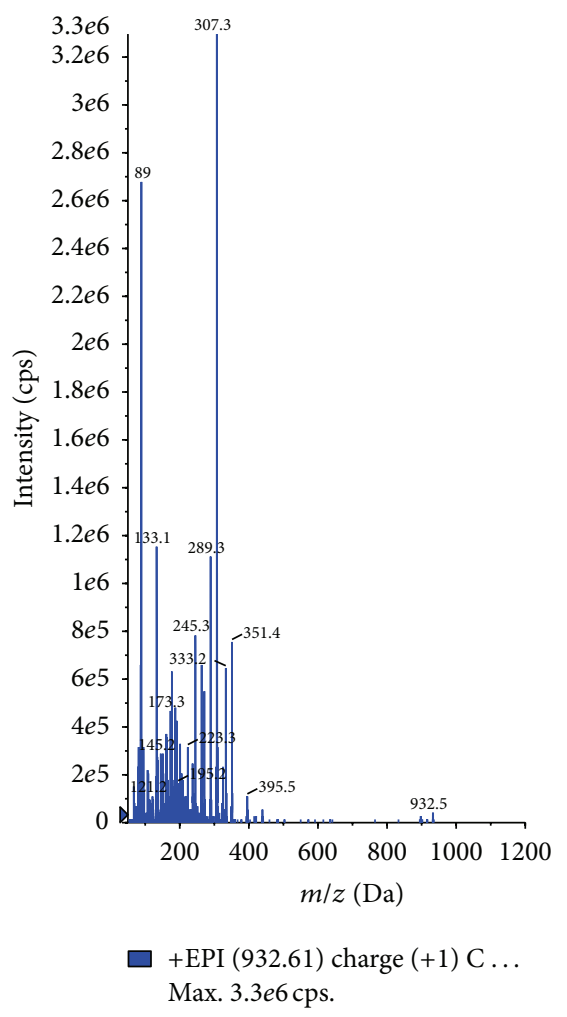

(b)

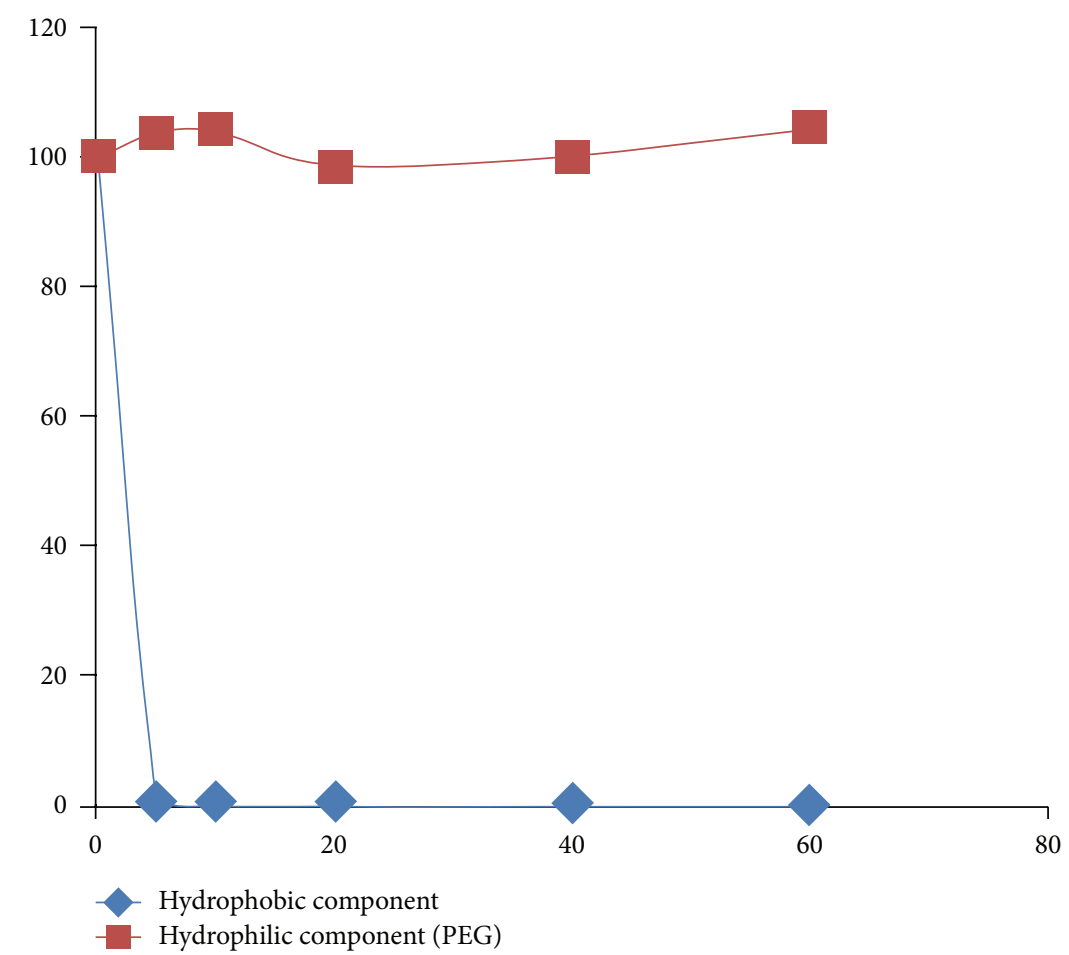

(c)

FIGURE 4: (a) Parent ion scan representing the molecular ions of hydrophobic oligomers (glycerol polyoxyethylene ricinoleate) of CrEL (b) Fragmentation pattern of selected oligomer with $\mathrm{m} / z$ 932.50. (c) Remaining percent versus time curve representing the plasma stability of hydrophilic and hydrophobic components of CrEL. 
TABLE 1: Calculated concentrations and statistical parameters of CrEL-PEG calibration standards prepared in rat plasma $(n=3)$.

\begin{tabular}{|c|c|c|c|c|c|c|c|}
\hline \multicolumn{4}{|c|}{ Concentration $(\mu \mathrm{g} / \mathrm{mL})$} & \multicolumn{4}{|c|}{ Statistical parameters } \\
\hline \multirow{2}{*}{ Actual conc. } & \multicolumn{3}{|c|}{ Calculated conc. } & \multirow{2}{*}{ Mean } & \multirow{2}{*}{ SD } & \multirow{2}{*}{ CV\% } & \multirow{2}{*}{ Relative error (\%) } \\
\hline & Set 1 & Set 2 & Set 3 & & & & \\
\hline 1.00 & 1.07 & 1.04 & 1.05 & 1.05 & 0.02 & 1.45 & 5.33 \\
\hline 1.50 & 1.40 & 1.41 & 1.41 & 1.41 & 0.01 & 0.41 & -6.22 \\
\hline 5.00 & 4.56 & 5.15 & 4.95 & 4.89 & 0.30 & 6.14 & -2.27 \\
\hline 20.00 & 18.84 & 19.05 & 18.54 & 18.81 & 0.26 & 1.36 & -5.95 \\
\hline 70.00 & 70.19 & 67.98 & 68.39 & 68.85 & 1.18 & 1.71 & -1.64 \\
\hline 120.00 & 122.31 & 122.36 & 127.58 & 124.08 & 3.03 & 2.44 & 3.40 \\
\hline 160.00 & 173.41 & 176.10 & 152.36 & 167.29 & 13.00 & 7.77 & 4.56 \\
\hline 180.00 & 187.32 & 174.58 & 194.31 & 185.40 & 10.00 & 5.40 & 3.00 \\
\hline 200.00 & 199.88 & 196.18 & 205.05 & 200.37 & 4.46 & 2.22 & 0.19 \\
\hline
\end{tabular}

TABLE 2: Precision and accuracy of CrEL-PEG in quality control samples.

\begin{tabular}{|c|c|c|c|c|}
\hline \multirow{2}{*}{ Type } & \multirow{2}{*}{ Statistical parameter } & \multicolumn{3}{|c|}{ Concentration $(\mu \mathrm{g} / \mathrm{mL})$} \\
\hline & & LQC (2.50) & MQC (125.00) & HQC (162.00) \\
\hline \multirow{4}{*}{ Intraday Set $1(N=6)$} & Mean & 2.47 & 130.93 & 164.61 \\
\hline & SD & 0.13 & 10.94 & 15.16 \\
\hline & $\mathrm{CV} \%$ & 5.19 & 8.36 & 9.21 \\
\hline & Relative error (\%) & -1.07 & 4.74 & 1.61 \\
\hline \multirow{4}{*}{ Intraday Set $2(N=6)$} & Mean & 2.31 & 124.65 & 163.33 \\
\hline & SD & 0.08 & 4.29 & 10.49 \\
\hline & $\mathrm{CV} \%$ & 3.60 & 3.45 & 6.42 \\
\hline & Relative error (\%) & -7.60 & -0.28 & 0.82 \\
\hline \multirow{4}{*}{ Intraday Set $3(N=6)$} & Mean & 2.43 & 123.34 & 165.59 \\
\hline & SD & 0.15 & 7.13 & 11.18 \\
\hline & CV\% & 6.08 & 5.78 & 6.75 \\
\hline & Relative error (\%) & -2.80 & -1.33 & 2.22 \\
\hline \multirow{4}{*}{ Interday $(N=3)$} & Mean & 2.40 & 126.31 & 164.51 \\
\hline & SD & 0.08 & 4.06 & 1.14 \\
\hline & CV\% & 3.52 & 3.21 & 0.69 \\
\hline & Relative error (\%) & -3.82 & 1.04 & 1.55 \\
\hline
\end{tabular}

3.2. Plasma Stability Determination of CrEL. Hydrophobic component was found very fastly hydrolyzing (ester hydrolysis) in rat plasma with $<1 \%$ remaining at $5 \mathrm{~min}$. This could be due to esterases present at higher levels in rat plasma causing hydrolysis of hydrophobic component of CrEL. Similarly, hydrophilic component was found stable in 60 min incubation period. As hydrophobic component was found highly unstable in the rat plasma, analysis of the free PEG oligomers (hydrophilic component) was taken up to understand the pharmacokinetic disposition of CrEL.

3.3. Method Validation. This method was validated to meet the acceptance criteria of industrial guidance for the bioanalytical method validation [28]. The nine-point calibration curve obtained for CrEL-PEG was linear over the concentration range of $1.00-200.00 \mu \mathrm{g} / \mathrm{mL}$ with mean correlation coefficient $\geq 0.9972$. The ratio of area response for CrELPEG and PPG (internal standard) was used for regression analysis. Of the two weighing models $(1 / x, 1 / x * x)$ used for curve fitting, linear regression analysis $(y=m x+c)$ with a weighting factor of $1 /(x * x)$ gave the optimum accuracy of the corresponding calculated concentrations at each level (Table 1). The mean accuracy (RE\%) and precision (CV\%) observed for the calibration curve standards ranged from -6.22 to $5.33 \%$ and 0.41 to $7.77 \%$, respectively. Table 2 shows a summary of intra- and interday precision and accuracy data for QC samples containing CrEL-PEG. Both intra- and interassay CV values ranged from 0.69 to $9.21 \%$ at three QC levels. The intra- and interassay RE values for CrEL-PEG were -7.60 to $4.74 \%$ at three QC levels. These results indicate that the present method has an acceptable accuracy and precision. As shown in Table 3, the overall extraction efficiency of CrEL-PEG was $103.23 \%$, which was consistent with a total CV\% less than 5\% at three QC concentration levels. Mean matrix factor values of 1.05 (Table 3) at three QC levels show that the developed method is totally free of matrix effects. 


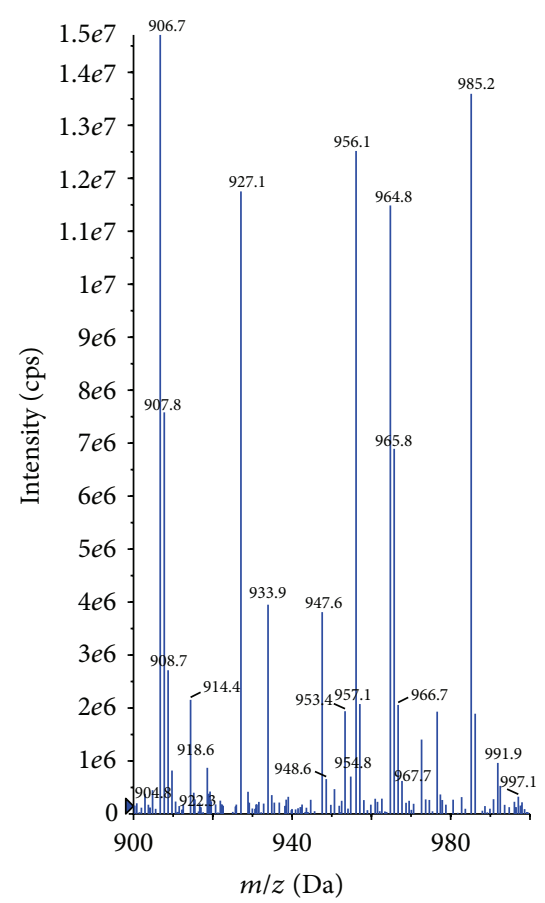

+Q1: 0.168 to $0.184 \mathrm{~min}$ fro ... Max. $1.5 e 7 \mathrm{cps}$.

(a)

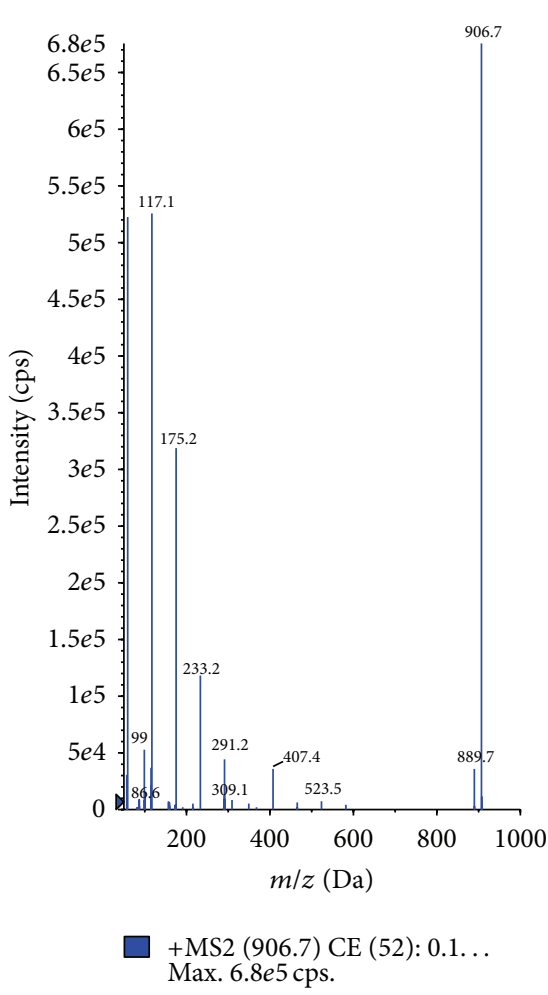

(b)

FIGURE 5: (a) Parent ion scan representing the molecular ions of PPG. (b) Fragmentation pattern for molecular ion of PPG with $m / z$ 906.70.

TABLE 3: Summary of validation parameters for CrEL-PEG in rat plasma.

\begin{tabular}{lcc}
\hline Validation parameter & Statistical parameter & Result \\
\hline \multirow{2}{*}{ Extraction recovery } & Mean & 103.23 \\
& SD & 5.28 \\
Matrix factor (matrix effect) & CV\% & 5.11 \\
\hline & SD & 1.05 \\
Autosampler stability & CV\% & 0.03 \\
& Mean & 2.87 \\
\hline \multirow{3}{*}{ Bench top stability } & SD & 101.04 \\
& CV\% & 3.71 \\
& Mean & 3.68 \\
\hline \multirow{3}{*}{ Freeze thaw stability } & SD & 103.05 \\
& CV\% & 2.07 \\
& Mean & 2.00 \\
\hline & SD & 100.73 \\
Long-term stability & CV\% & 4.55 \\
& Mean & 4.52 \\
\hline
\end{tabular}

Acceptable matrix factor range for qualifying the method to be free from matrix effects is $0.85-1.15$. Protein precipitation has been successfully applied to the extraction of CrELPEG from rat plasma. Extracted QC samples were stable when stored at $4^{\circ} \mathrm{C}$ for $24 \mathrm{~h}$ (autosampler stability) prior to injection, with $<4 \%$ difference from theoretical concentration (Table 3). Spiked QC samples were stable when stored at room temperature for $8 \mathrm{~h}$ (bench top stability) prior to injection, with $<2 \%$ (Table 3 ) difference from theoretical concentration. Spiked QC samples were stable for three freeze thaw cycles (freeze thaw stability) with $<5 \%$ difference from theoretical concentration. Long-term stability at $-80^{\circ} \mathrm{C}$ was proved for a period of 90 days with $<3 \%$ (Table 3 ) difference from theoretical concentration (Table 3 ).

3.4. Application Study. This method has been successfully applied to the bioanalysis of rat plasma samples in absolute bioavailability study of CrEL. Representative chromatograms of CrEL-PEG from intravenous $(0.50 \mathrm{hr})$, oral $(0.50 \mathrm{hr})$ study samples were shown in Figures 6(e) and 6(f) respectively. The Intravenous and oral concentration/time profiles of CrELPEG is represented in Figures 7 (a) and 7(b), respectively. As CrEL-PEG a clear absorption and elimination phase in oral route of administration and clear elimination phase in intravenous route of administration, measuring the excipient concentration levels along with NCEs helps to take a decision on the spiky profile of NCEs. Monitoring formulation excipient concentrations in PK study samples acts as quality control check for in vivo and bioanalytical processes. Intravenous and oral Pharmacokinetic parameters of CrEL-PEG were listed in 


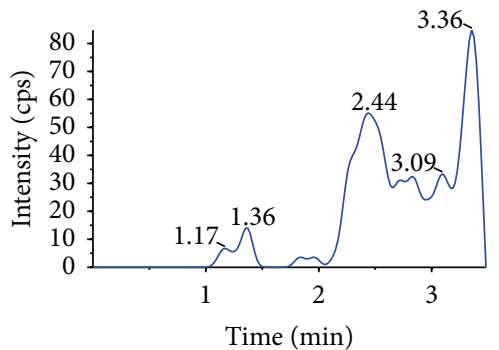

Sample name: "BLK” Sample ID: “” File: “002.wiff”

Peak name: "ISTD (PPG)(IS)” Mass(es): “907.2/117.1. . Comment: "” Annotation: "'”

(a)



Sample name: "CREL-STD-1" Sample ID: “” File: “00. . .

Peak name: “ISTD (PPG)(IS)” Mass(es): “907.2/117.1. . Comment: "” Annotation: “"

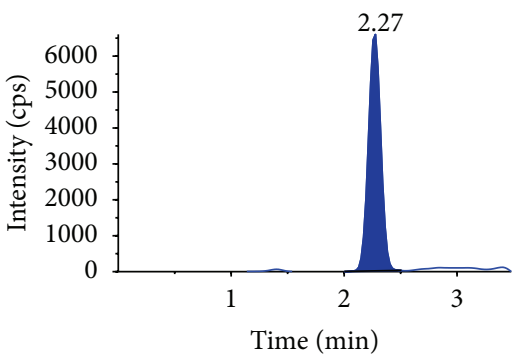

Sample name: "IV-CREL-0.5HR-1" Sample ID: "” Fil.. Peak name: "ISTD (PPG)(IS)” Mass(es): “907.2/117.1. . Comment: "” Annotation: "”

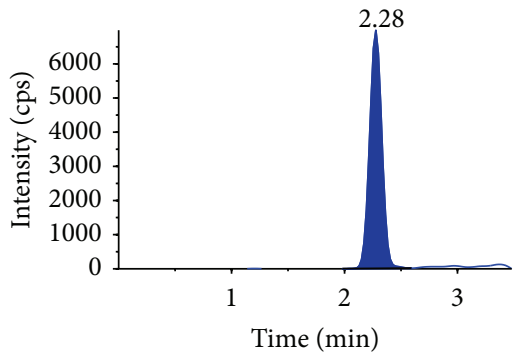

Sample name: "PO-CREL-0.5HR-1" Sample ID: “" Fi. Peak name: "ISTD (PPG)(IS)" Mass(es): "907.2/117.1. . Comment: "” Annotation: "”

(c)

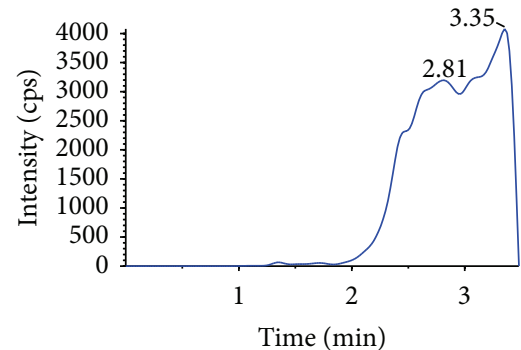

Sample name: "BLK” Sample ID: "” File: “002.wiff”

Peak name: "GLY-POE” Mass(es): “828.5/89.1 Da, 872. .

Comment: "” Annotation: "”

(b)

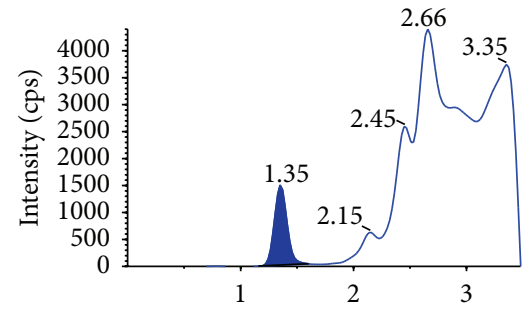

Time (min)

Sample Name: "CREL-STD-1" Sample ID: “” File: “00. .

Peak name: "GLY-POE” Mass(es): “828.5/89.1 Da, 872. . Comment: "” Annotation: "”

(d)



Sample name: "IV-CREL-0.5HR-1" Sample ID: "” Fil...

Peak name: "GLY-POE” Mass(es): “828.5/89.1 Da, 872. . Comment: "” Annotation: "’”

(e)

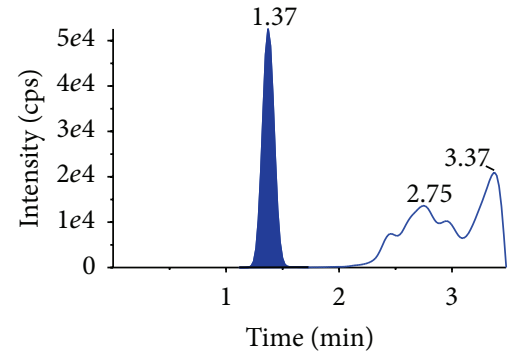

Sample name: "PO-CREL-0.5HR-1" Sample ID: “” Fi. .

Peak name: "GLY-POE” Mass(es): “828.5/89.1 Da, 872. . Comment: "” Annotation: “”

(f)

Figure 6: MRM LC-MS/MS chromatograms of (a) PPG in blank rat plasma; (b) CrEL-PEG in rat blank plasma; (c) PPG spiked at $10 \mu \mathrm{g} / \mathrm{mL}$ concentration in rat plasma; (d) Rat plasma sample spiked with $1.00 \mu \mathrm{g} / \mathrm{mL}$ of CrEL-PEG; (e) plasma sample obtained $0.50 \mathrm{hr}$ after intravenous administration of CrEL to SD rats; (f) plasma sample obtained $0.50 \mathrm{hr}$ after oral administration of CrEL to SD rats. 
TABLE 4: Pharmacokinetic parameters of CrEL-PEG after intravenous administration at $0.018 \mathrm{~g} / \mathrm{kg}$ dose (PEG Oligomers) in male Sprague Dawley rats.

\begin{tabular}{lccccccccc}
\hline Subject & $\begin{array}{c}\text { Kel } \\
(1 / \mathrm{hr})\end{array}$ & $T_{1 / 2}(\mathrm{hr})$ & $C_{0}(\mu \mathrm{g} / \mathrm{mL})$ & $\begin{array}{c}\text { AUClast } \\
(\mathrm{hr} * \mu \mathrm{g} / \mathrm{mL})\end{array}$ & $\begin{array}{c}\text { AUCINF_obs } \\
(\mathrm{hr} * \mu \mathrm{g} / \mathrm{mL})\end{array}$ & $\begin{array}{c}\text { AUC_\%Extrap_obs } \\
(\%)\end{array}$ & $\begin{array}{c}\text { Vz_obs } \\
(\mathrm{L} / \mathrm{kg})\end{array}$ & $\begin{array}{c}\text { Cl_obs } \\
(\mathrm{mL} / \mathrm{min} / \mathrm{kg})\end{array}$ & $\begin{array}{c}\text { MRTlast } \\
(\mathrm{hr})\end{array}$ \\
\hline RAT-1 & 0.11 & 6.29 & 834.53 & 1714.61 & 1849.94 & 7.32 & 0.13 & 0.24 \\
RAT-2 & 0.08 & 8.17 & 745.12 & 1566.77 & 1794.63 & 12.70 & 0.17 & 0.24 \\
RAT-3 & 0.08 & 8.50 & 609.02 & 1620.79 & 1886.80 & 14.10 & 0.17 & 0.23 \\
Mean & 0.09 & 7.65 & 729.56 & 1634.06 & 1843.79 & 11.37 & 0.16 & 0.24 \\
SD & 0.02 & 1.19 & 113.56 & 74.81 & 46.39 & 3.58 & 0.02 & 0.01 \\
CV\% & 17.03 & 15.60 & 15.56 & 4.58 & 2.52 & 31.49 & 15.73 & 2.53 & 0.86 \\
\hline
\end{tabular}

TABLE 5: Pharmacokinetic parameters of CrEL-PEG after oral administration at $0.018 \mathrm{~g} / \mathrm{kg}$ dose (PEG component) in male Sprague Dawley rats.

\begin{tabular}{|c|c|c|c|c|c|c|c|c|c|c|c|}
\hline Subject & $\begin{array}{c}\text { Kel } \\
(1 / \mathrm{hr})\end{array}$ & $\begin{array}{l}T_{1 / 2} \\
(\mathrm{hr})\end{array}$ & $\begin{array}{l}T_{\max } \\
(\mathrm{hr}) \\
\end{array}$ & $\begin{array}{c}C_{\max } \\
(\mu \mathrm{g} / \mathrm{mL})\end{array}$ & $\begin{array}{c}\text { AUClast } \\
(\mathrm{hr} * \mu \mathrm{g} / \mathrm{mL})\end{array}$ & $\begin{array}{c}\text { AUCINF_obs } \\
(\mathrm{hr} * \mu \mathrm{g} / \mathrm{mL})\end{array}$ & $\begin{array}{c}\text { AUC_\%Extrap } \\
\text { obs (\%) }\end{array}$ & $\begin{array}{c}\text { Vz_F_obs } \\
(\mathrm{L} / \mathrm{kg})\end{array}$ & $\begin{array}{c}\text { Cl_F_obs } \\
(\mathrm{mL} / \mathrm{min} / \mathrm{kg})\end{array}$ & $\begin{array}{c}\text { MRTlast } \\
(\mathrm{hr})\end{array}$ & $F(\%)$ \\
\hline RAT-1 & 0.61 & 1.14 & 0.50 & 18.42 & 45.01 & 49.82 & 9.67 & 0.86 & 8.78 & 1.62 & 2.62 \\
\hline RAT-2 & 0.85 & 0.82 & 0.50 & 30.50 & 46.85 & 49.07 & 4.52 & 0.63 & 8.92 & 1.31 & 2.99 \\
\hline RAT-3 & 0.38 & 1.84 & 0.50 & 24.45 & 45.29 & 48.21 & 6.04 & 1.44 & 9.08 & 1.93 & 2.79 \\
\hline Mean & 0.61 & 1.26 & 0.50 & 24.46 & 45.72 & 49.03 & 6.74 & 0.98 & 8.92 & 1.62 & 2.80 \\
\hline SD & 0.23 & 0.52 & 0.00 & 6.04 & 0.99 & 0.81 & 2.64 & 0.42 & 0.15 & 0.31 & 0.18 \\
\hline CV\% & 38.39 & 41.22 & 0.00 & 24.70 & 2.17 & 1.65 & 39.20 & 42.66 & 1.65 & 19.18 & 6.52 \\
\hline
\end{tabular}

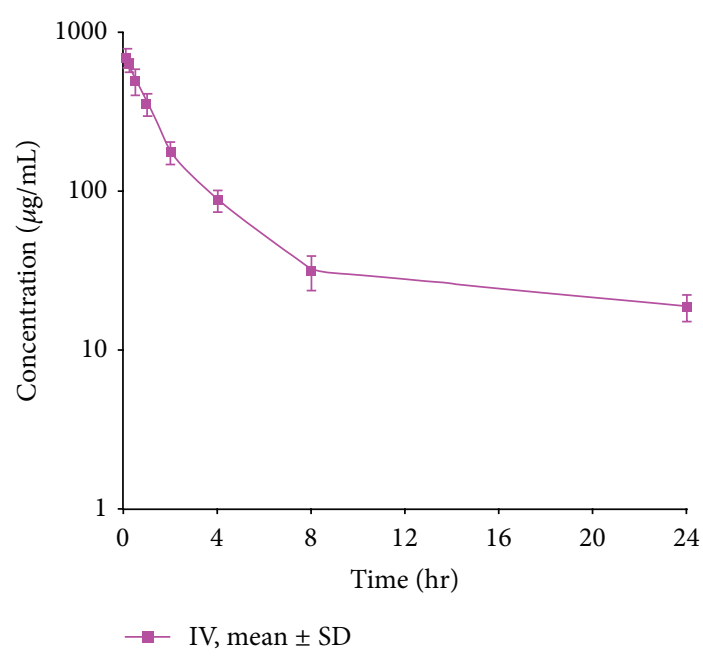

(a)

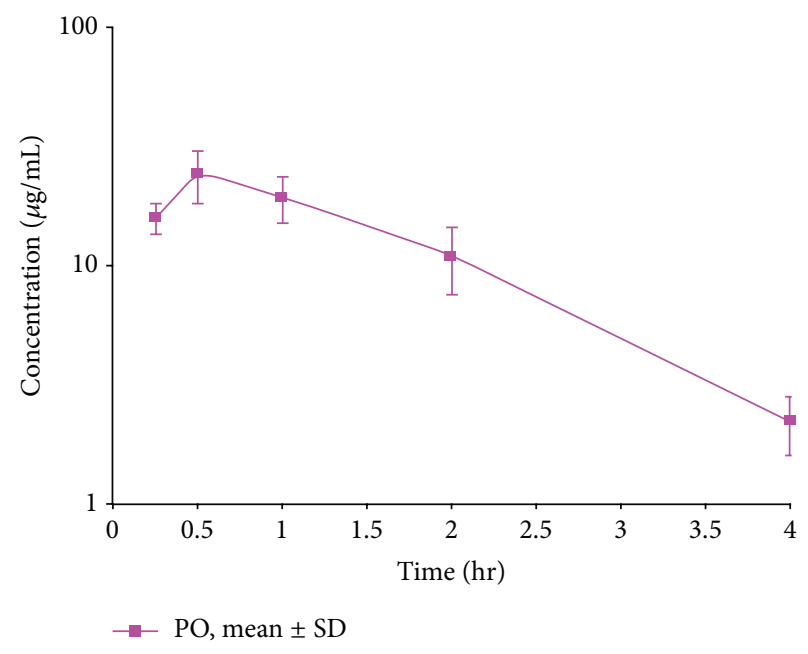

(b)

FIGURE 7: Mean Concentration time profile of CrEL (CEL-PEG) after (a) intravenous administration at $0.018 \mathrm{~g} / \mathrm{kg}$ (PEG component) dose to $\mathrm{SD}$ rats (b) oral administration at $0.018 \mathrm{~g} / \mathrm{kg}$ (PEG component) dose to SD rats.

Tables 4 and 5 respectively. The oral bioavailability of CrELPEG was measured as $2.80 \%$ which shows that the excipient had very poor absorption. Mean terminal half-life of CrELPEG after oral and intravenous administration was $1.26 \mathrm{hr}$ and $7.65 \mathrm{hr}$ respectively. Mean Tmax and Cmax after oral administration of CrEL-PEG to Sprague Dawley rats was $0.50 \mathrm{hr}$ and $24.46 \mu \mathrm{g} / \mathrm{mL}$, respectively. Mean residence time of CrEL-PEG after intravenous and oral administration of CrEL to Sprague dawley rats was 5.25 and 1.62, respectively. Mean volume of distribution after intravenous administration $(0.16 \mathrm{~L} / \mathrm{kg})$ was much lesser than total normalized body water $0.7 \mathrm{~L} / \mathrm{kg}$ in rats. Mean clearance of CrEL-PEG after intravenous administration was much less $(0.24 \mathrm{~mL} / \mathrm{min} / \mathrm{kg}$ body wt) than hepatic blood flow in rats $(70 \mathrm{~mL} / \mathrm{min} / \mathrm{kg}$ body $w t)$.

\section{Conclusion}

A rapid, sensitive, and selective LC-MS/MS method for the determination of CrEL-PEG in rat plasma has been successfully developed and validated using protein precipitation extraction as sample preparation procedure. This 
assay method demonstrated acceptable sensitivity (LLOQ: $1.00 \mu \mathrm{g} / \mathrm{mL}$ ), precision, accuracy, selectivity, recovery, and stability. The validated method was successfully applied to assay rat plasma samples. The plasma concentration profiles/PK parameters of CrEL after intravenous and oral administration in male Sprague Dawley rats were established.

\section{References}

[1] F. L. S. Tse and J. M. Jaffe, Preclinical Drug Disposition (Drugs and the Pharmaceutical Sciences), Marcel Dekker, New York, NY, USA, 1991.

[2] L. K. Webster, D. M. Woodcock, D. Rischin, and M. J. Milliward, "Cremophor: pharmacological activity of an inert solubiliser," Journal of Oncology Pharmacy Practice, vol. 3, pp. 186-192, 1997.

[3] T. Meyer, D. Waidelich, and A. W. Frahm, "Polyoxyethylene$\Delta 9,11$-didehydrostearate and glycerol-polyoxyethylene- $\Delta 9,11-$ didehydrostearate: two new components of the non-ionic emulsifier Cremophor EL," Journal of Pharmaceutical and Biomedical Analysis, vol. 30, no. 2, pp. 263-271, 2002.

[4] A. Sparreboom, W. J. Loos, J. Verweij et al., "Quantitation of cremophor EL in human plasma samples using a colorimetric dye-binding microassay," Analytical Biochemistry, vol. 255, no. 2, pp. 171-175, 1998.

[5] N. Authier, J. P. Gillet, J. Fialip, A. Eschalier, and F. Coudore, "Description of a short-term Taxol-induced nociceptive neuropathy in rats," Brain Research, vol. 887, no. 2, pp. 239-249, 2000.

[6] A. J. Windebank, M. D. Blexrud, and P. C. De Groen, "Potential neurotoxicity of the solvent vehicle for cyclosporine," Journal of Pharmacology and Experimental Therapeutics, vol. 268, no. 2, pp. 1051-1056, 1994.

[7] S. H. Burstein, E. Friderichs, B. Kögel, J. Schneider, and N. Selve, "Analgesic effects of 1,1' dimethylheptyl- $\delta 8$-thc 11 -oic acid (ct3) in mice," Life Sciences, vol. 63, no. 3, pp. 161-168, 1998.

[8] P. A. J. Janssen, C. J. E. Niemeggers, and J. G. H. Dony, “The inhibitory effect of fentanyl and other morphine-like analgesics on the warm water induced tail withdrawal reflex in rats," Arzneimittel Forschung, vol. 13, pp. 502-507, 1963.

[9] P. Mounier, D. Laroche, F. Divanon et al., "Anaphylactoid reactions after intravenous infusion of a cremophor-containing solution of multivitamins," Therapie, vol. 50, no. 6, pp. 571-573, 1995.

[10] F. K. Zhao, L. F. Chuang, M. Israel, and R. Y. Chuang, "Cremophor EL, a widely used parenteral vehicle, is a potent inhibitor of protein kinase C," Biochemical and Biophysical Research Communications, vol. 159, no. 3, pp. 1359-1367, 1989.

[11] A. M. Jack, N. E. Cameron, and M. A. Cotter, "Effects of the diacylglycerol complexing agent, cremophor, on nerveconduction velocity and perfusion in diabetic rats," Journal of Diabetes and its Complications, vol. 13, no. 1, pp. 2-9, 1999.

[12] H. Gelderblom, J. Verweij, D. M. Van Zomeren et al., "Influence of cremophor EL on the bioavailability of intraperitoneal paclitaxel," Clinical Cancer Research, vol. 8, no. 4, pp. 1237-1241, 2002.

[13] E. Brouwer, J. Verweij, B. Hauns et al., "Linearized colorimetric assay for cremophor EL: application to pharmacokinetics after 1-hour paclitaxel infusions," Analytical Biochemistry, vol. 261, no. 2, pp. 198-202, 1998.

[14] A. Sparreboom, O. Van Tellingen, M. T. Huizing, W. J. Nooijen, and J. H. Beijnen, "Determination of polyoxyethyleneglycerol triricinoleate 35 (Cremophor EL) in plasma by pre-column derivatization and reversed-phase high-performance liquid chromatography," Journal of Chromatography B, vol. 681, no. 2, pp. 355-362, 1996.

[15] F. M. Eiabbes, T. Dine, M. Luyckz et al., "Stability, compatibility and plasticizer extraction of miconazole injection added to infusion solutions and stored in PVC containers," Journal of Pharmaceutical and Biomedical Analysis, vol. 13, pp. 1363-1372, 1995.

[16] M. T. Huizing, H. Rosing, F. P. Koopmans, and J. H. Beijnen, "Influence of Cremophor EL on the quantification of paclitaxel in plasma using high-performance liquid chromatography with solid-phase extraction as sample pretreatment," Journal of Chromatography B, vol. 709, no. 1, pp. 161-165, 1998.

[17] M. Kunkel, J. Böhler, E. Keller, and A. W. Frahm, "Separation of Cremophor EL by capillary electrophoresis," Pharmazie, vol. 52, no. 2, pp. 109-121, 1997.

[18] M. Kunkel, J. Böhler, E. Keller, and A. W. Frahm, "Titrimetric determinations of Cremophor EL in biofluids," Pharmazie, vol. 53, no. 5, pp. 314-321, 1998.

[19] M. Kunkel, T. Meyer, J. Böhler, E. Keller, and A. W. Frahm, "Titrimetric determination of Cremophor EL in aqueous solutions and biofluids-Part 2: ruggedness of the method with respect to biofluids," Journal of Pharmaceutical and Biomedical Analysis, vol. 21, no. 5, pp. 911-922, 1999.

[20] T. Meyer, J. Böhler, and A. W. Frahm, "Determination of Cremophor EL in plasma after sample preparation with solid phase extraction and plasma protein precipitation," Journal of Pharmaceutical and Biomedical Analysis, vol. 24, no. 3, pp. 495506, 2001.

[21] M. Carbini, R. Stevanato, M. Rovea, P. Traldi, and D. Favretto, "Curie-point pyrolysis-gas chromatography/mass spectrometry in the art field. 2-The characterization of proteinaceous binders," Rapid Communications in Mass Spectrometry, vol. 10, pp. 12401242, 1996.

[22] J. J. Boon, "Analytical pyrolysis mass spectrometry: new vistas opened by temperature-resolved in-source PYMS," International Journal of Mass Spectrometry and Ion Processes, vol. 118119, pp. 755-787, 1992.

[23] S. Neervannan, "Preclinical formulations for discovery and toxicology: physicochemical challenges," Expert Opinion on Drug Metabolism and Toxicology, vol. 2, no. 5, pp. 715-731, 2006.

[24] P. Li and L. Zhao, "Developing early formulations: practice and perspective," International Journal of Pharmaceutics, vol. 341, no. 1-2, pp. 1-19, 2007.

[25] Y. Kwon, Pharmacokinetic Study Design and Data Interpretation, Kluwer Academic, New York, NY, USA, 2002.

[26] “Agilent solutions guide," Polymer and Hydrocarbon Processing Solutions with HPLC 5968-7020E, 1999.

[27] N. Andreas, W. V. V. Jan, M. A. H. Ron, and F. V. D. B. Oscar, "Detailed molecular characterization of castor oil ethoxylates by liquid chromatography multi stage mass spectrometry," Journal of Chromatography A, vol. 1218, pp. 7166-7172, 2011.

[28] US Department of Health and Human Services, Guidance for Industry-Bioanalytical Method Validation, Food and Drug Administration, Center for Drug Evaluation and Research, Center for Veterinary Medicine, 2001. 

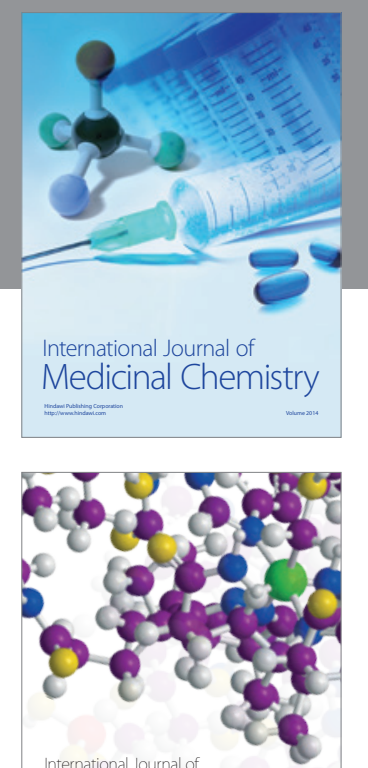

\section{Carbohydrate} Chemistry

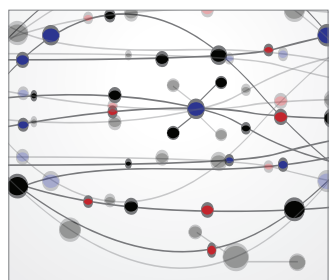

The Scientific World Journal
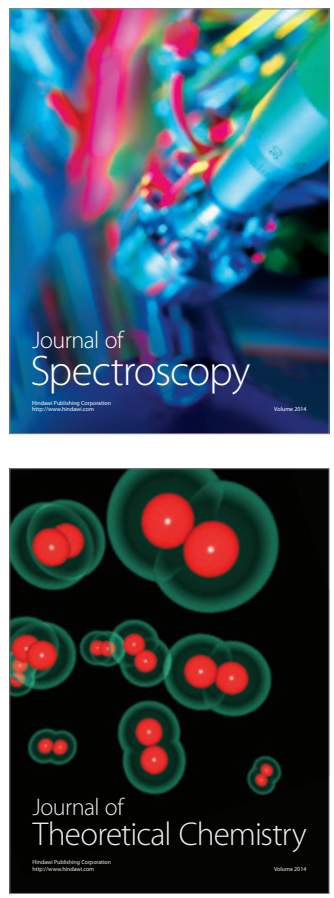
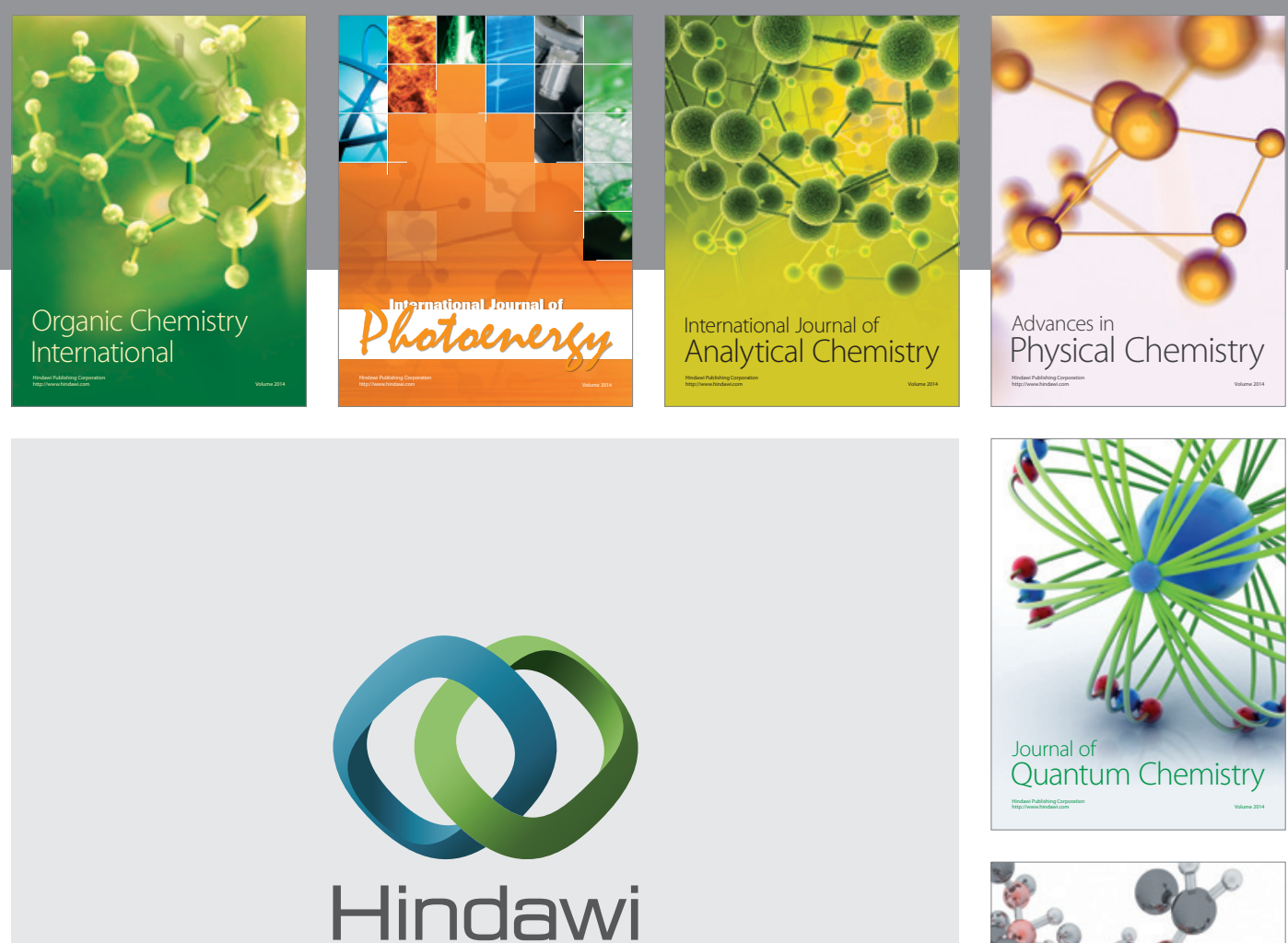

Submit your manuscripts at

http://www.hindawi.com



Analytical Methods

in Chemistry



Journal of

Applied Chemistry

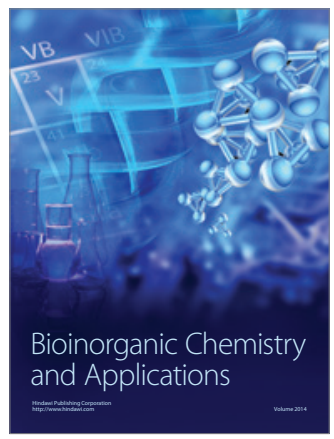

Inorganic Chemistry
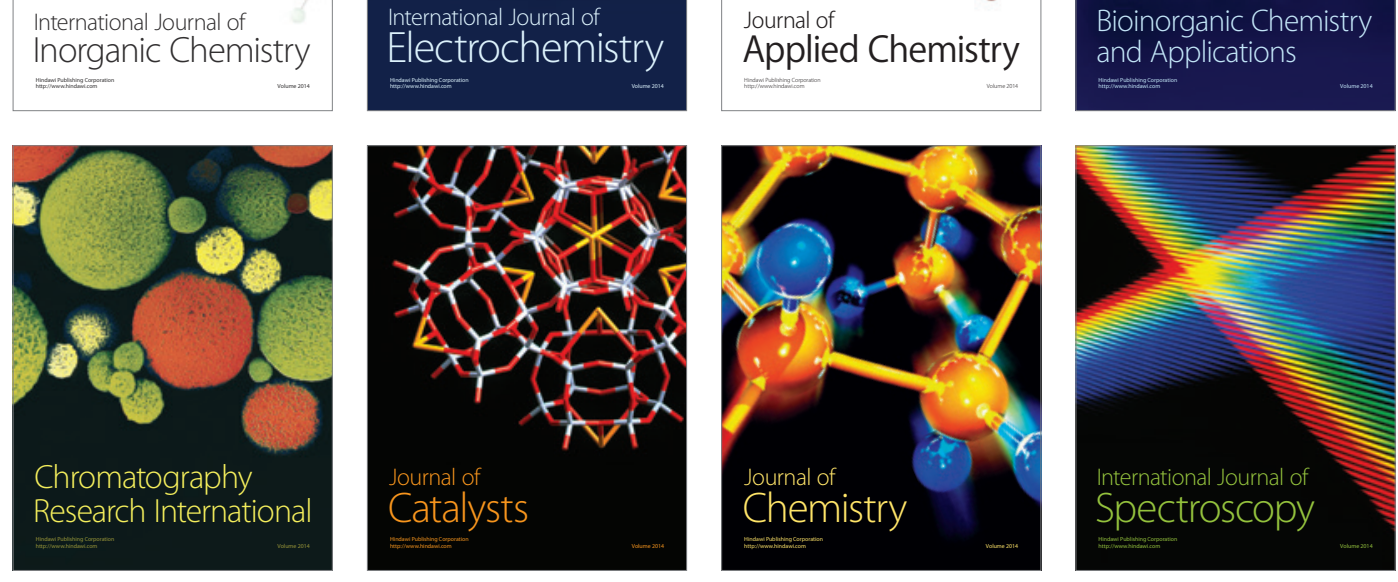